\title{
STUDI KASUS PEMENUHAN KEBUTUHAN DEFISIT PERAWATAN DIRI MANDI DAN BERHIAS PADA PASIEN ISOLASI SOSIAL DI RUMAH SAKIT TINGKAT II PELAMONIA MAKASSAR
}

Case Study Of Fulfillment Of Self-Care Deficit Showering And Decorating Needs In Social Isolation Patients At Pelamonia Level Il Hosiptal Makassar

Rahman $^{1}$

Muhammad Nur ${ }^{2}$

1 Jurusan Keperawatan Politeknik Kesehatan Kemenkes Makassar

2Jurusan Keperawatan Politeknik Kesehatan Kemenkes Makassar Corresponding author: rahman.nasar63@gmail.com

\begin{abstract}
Background: Psychological health in this era has become global health in every state including in Indonesia. The process of globalization and the increasing of sophisticated technology of information, giving value effect to social and culture of society, not all people have the same capacity for adjusting of change and also managing conflict and stress, so that resulting many people experience of psychological disturbance, even they are not able to treat sanitation of themselves. Least of health care to medical patient of physical disturbance has occurred because there is a changing of logical thinking so that the capacity for doing activities is decreased. Purpose: for identifying the capability of Mr.A, Mr.M and Mr.R for filling of necessity deficit of health care, showering and dressing up with interviewing method, observation method, and documentation.Result. : After doing an observation, the researcher gets the result that Mr.A can do treatment or healthcare especially for showering and dressing up, but Mr.M and Mr.R are not able to do healthcare of self-treatment especially for showering and dressing up. The reason why a client can not do self-treatment caused of the lack of supporting and motivation, and also exercising of the capability to do self-treatment, especially for showering and dressing up from their close relation and lack of devices providing to health care. And the patients are getting weak to do activities. So, they can not do self-treatment or health care. Conclusion: The encouraging of their close relationship can make the patients do selftreatment, so that, the patients are expected to be more spirit and more motivated to do self-treatment and make them be able to survive their self-treatment.
\end{abstract}

Key words : study of case, deficit of health care.

\section{ABSTRAK}

Latar Belakang: kesehatan jiwa saat ini telah menjadi masalah kesehatan global di setiap negara termasuk di Indonesia. Proses globalisasi dan pesatnya kemajuan teknologi informasi memberikan dampak terhadap nilai-nilai sosial dan budaya pada masyarakat. Tidak semua orang mempunyai kemampuan yang sama untuk menyesuaikan dengan perubahan, serta mengelola komflik dan stress tersebut sehingga mengakibatkan banyak orang yang mengalami gangguan jiwa bahkan tidak mampu dalam merawat kebersihan dirinya. Kurangnya perawatan diri pada pasien dengan ganguan jiwa terjadi akibat adanya perubahan proses pikir sehingga kemampuan dalam melakukan aktivitas perawatan diri menurun. Tujuan: untuk mengidentifikasi kemampuan Tn.A, Tn.M dan Tn.R dalam pemenuhan kebutuhan defisit perawatan diri mandi dan berhias dengan metode indepth interview,observasi, dan dokumentasi. Hasil: Setelah dilakukan penelitian didapatkan hasil bahwa Tn.A mampu melakukan perawatan diri sedangkanTn.M dan Tn. R tidak mampu melakukan perawatan diri, hal yang membuat klien tidak mampu melakukan perawatan diri yaitu kurangnya dukungan motivasi dan latihan kemampuan perawatan diri khususnya mandi dan berhias dari orang terdekat dan kurangnya ketersediaan alat dan bahan perawatan diri serta kelemahan dalam melakukan aktivitas sehingga memgakibatkan ketidak mampuan melakukan perawatan diri. Kesimpulan: dukungan dari orang terdekat mampu membuat pasien melakukan perawatan diri sehingga diharapkan pasien bersemangat dan mempunyai motivasi untuk mekakukan perawatan diri dan juga membuat pasien yang mampu dapat mempertahankan kemampuan perawatan dirinya.

Kata kunci :Studi Kasus, Defisit Perawatan Diri

\section{PENDAHULUAN}

Perkembangan jaman menurut kehidupan manusia semakin modern, begitu juga semakin bertambahnya stressorpsikososial akibat budaya masyarakat modern yang cenderung lebih sekuler, hal ini dapat menyebabkan manusia semakin sulit 
menghadapi tekanan-tekanan hidup yang datang. Kondisi kritis ini juga membawa dampak terhadap peningkatan kualitas maupun kuantitas penyakit mental emosional manusia. Sebagai akibat maka akan timbul gangguan jiwa khususnya pada ganggguan isolasi sosial: Menarik diri dalam tingkat ringan ataupun berat yang memerlukan penanganan dirumah sakit baik dirumah sakit jiwa atau diunit perawatan jiwa dirumah sakit umum (Nurjannah, 2005).

Berdasarkan hasil Riset Kesehatan Dasar (Riskesdas) tahun 2007 dari Badan Penelitian Pengembangan Kesehatan Kemenkes Republik Indonesia (Kemenkes Rl, 2008), prevalensi gangguan mental emosional seperti gangguan kecemasan dan depresi sebesar $11,6 \%$ dari populasi orang dewasa dengan prevalensi tertinggi di Jawa Barat yaitu 20,0\%. Prevalensi gangguan jiwa berat di Indonesia sebesar $0,46 \%$, dengan kata lain dari 1000 penduduk Indonesia empat sampai lima diantaranya menderita gangguan jiwa berat. Prevalensi gangguan jiwa berat di Jawa Barat sebesar $0,22 \%$ dan angka tersebut meningkat menjadi $0,40 \%$ di kota Bogor (Rochmawati, Dwi, Anna, \& Wardani, 2013).

Penelitian Menurut data Word Health organization (WHO) atau Badan Kesehatan Dunia 2016, terdapat sekitar 60 juta orang terkena gangguan jiwa, 35 juta orang terkena depresi, 21 juta orang terkena skizofrenia, serta 4,5 juta terkena dimensia. Di Indonesia jumlah kasus gangguan jiwa terus bertambah yang berdambak pada penambahan beban negara dan penurunan produktifitas manusia untuk jangka panjang ini semua dengan berbagai faktor diantaranya: faktorbiologis, psikologis dan sosial dengan keanekaragaman penduduk. Berdasarkan Riset Kesehatan Dasar (Riskesdas, 2018) oleh Badan Penelitian dan Pengembangan Kementrian Kesehatan (Kemenkes) dilakukan pada 300.000 sampel rumah tangga (1,2 juta jiwa) di 34 provinsi, 416 kabupaten dan 98 kota. Dari sejumlah data dan informasi kesehatan, poin tentang gangguan jiwa mengungkap peningkatan proporsi cukup signifikan. Sebab, jika dibandingkan dengan Riskesdas 2013 naik dari 1,7\% menjadi $7 \%$.

Dalam penelitian (Rochmawati, dkk., 2013), telah dibuktikan bahwa macam-macam gangguan jiwa, HDR, Halusinasi, RPK, Menarik Diri dan DPD perlu komunikasi terapeutik. Komunikasi perawat dengan pasien jiwa mempunyai efek penyembuhan baik dalam konteks kesehatan jiwa maupun kesehatan fisik klien dengan defisit perawatan diri ( Madalise, dkk., 2015). Komunikasi juga memiliki konstribusi yang signifikan dalam kesehatan dan kesembuhan klien dalam perawatan diri. Komunikasi dalam bentuk strategi pelaksanaan pada defisit perawatan diri ini bertujuan agar klien mampu dan menjadi mau melakukan aktivitas perawatan diri secara mandiri (Katrili, 2015). Dalam proses keperawatan komunikasi terapeutik sangat penting karena komunikasi ini merupakan alat dalam melaksanakan proses keperawatan.

Adapun di provinsi sulawesi selatan, Berdasarkan profil kesehatan 2015, tercatat sebanyak 129,665 orang menderita gangguan jiwa dari 8.432.169 jumlah penduduk secara keseluruhan sedangkan di tahun 2016 menurun sebanyak 1,7 per 1000 penduduk (Dinkes,Sulsel 2015-2016). Sedangkan berdasarkan data RS Tk. II Pelamonia tahun 2016, Jumlah pasien yang mengalami Isolasi Sosial sebanyak 83 orang dari 229 orang yang mengalami gangguan jiwa, kemudian menurun pada tahun 2017 menjadi 41 orang dari 155 pasien yang mengalami gangguan jiwa.

Berdasarkan uraian tersebut di atas penulis tertarik untuk melakukan penelitian tentang studi kasus pemenuhan kebutuhan defisit perawatan diri (mandi dan berhias) pada pasien isolasi sosial. Diketahuinya gambaran perawatan diri (mandi) pada pasien Isolasi Sosial.

\section{METODE}

studi kasus ini menggunakan metode deskriptif kualitatif yang dilaksanakan dengan menetapkan tiga sampel pasien yang berbeda tetapi mengalami masalah keperawatan yang sama, yaitu gangguan isolasi sosial. Desain studi kasus digunakan untuk menggambarkan asuhan keperawatan pada pasien isolasi sosial dalam pemenuhan kebutuhan mandi dan berhias.

Tujuan dari desain studi kasus yang digunakan ini adalah untuk mengetahui lebih dalam mengenai asuhan keperawatan dengan defisit perawatan diri terhadap pasien isolasi sosial: menarik diri.

\section{Subjek Studi Kasus}

Subjek pada studi kasus ini merupakan tiga pasien isolasi sosial: menarik diri dengan defisit perawatan diri di Rumah Sakit Tk. II Pelamonia. Dengan kriteria sebagai berikut :

Kriteria inklusi :

1. Pasien gangguan isolasi sosial : menarik diri dengan masalah defisit perawatan diri (mandi dan berhias)

2. Pasien yang telah mendapatkan perawatan dan pengobatan minimal selama satu minggu

3. Sudah dapat berkomunikasi atau berinteraksi dengan perawat

4. Pasien yang bersedia menjadi responden

Kriteria eksklusi:

1. Gangguan fisik yang serius misalnya adanya penyakit kanker kronik

2. lari dari rumah sakit atau pulang paksa 
Fokus Studi

Pada fokus studi kasus ini adalah penerapan prosedur pemberian pemenuhan kebutuhan mandi dan berhias pada pasien isolasi sosial di Rumah Sakit Tk. II Pelamonia.

Peneliti melakukan penelitian dengan 3 informan dengan kasus yang sama yaitu klien isolasi sosial menarik diri dengan pemenuhan kebutuhan defisit perawatan diri mandi dan berhias di Rumah Sakit Tk.II Pelamonia Makassar. Penelitian ini dilakukan pada tanggal $17 \mathrm{~s} / \mathrm{d} 28$ Juni 2019. Metode pengumpulan data yang digunakan dengan wawancara, Observasi, dan Dokumentasi.

\section{HASIL}

Adapun hasil penelitian dapat diuraikan dibawah ini.

a. Hasil wawancara pasien isolasi sosial dengan pemenuhan kebutuhan mandi dan berhias

1. Kemampuan Mandi

Berdasarkan hasil wawancara yang dilakukan peneliti kepada informan "A" tidak mampu mejawab pertanyaan yang di berikan yaitu mengenai manfaat dan tujuan perawatan mandi itu apa, sebagai berikut: "saya tidak mengetahui manfaat dan tujuannya perawatan mandi itu apa karena saya tidak pernah dijelaskan sebelumnya dengan perawat kita hanya langsung di arahkan melakukan perawatan mandi"(17 juni 2019).

Sama halnya yang disampaikan oleh informan "M" senanda dengan yang telah disampaikan oleh informan "A"sebagai berikut: "saya tidak mengetahui apa itu manfaat dan tujuan perawatan mandi"(17 Juni 2019)

Lain halnya dengan informan "R" : "mandi itu supaya bersih tapi saya malas untuk melakukannya" (17 Juni 2019)

Berdasarkan hasil wawancara dan observasi yang dilakukan peneliti kepada informan "A" mampu menyebutkan dan mempersiapkan alat dan bahan untuk mandi, sebagai berikut: "sebelum ke kamar mandi saya di panggil terlebih dahulu maju kedepan untuk mengambil dan mempersiapkan alat dan bahan yang akan digunakan untuk melakukan perawatan mandi seperti sabun mandi, sikat gigi, odol, shampo, dan handuk" (17 Juni 2019)

Lain halnya yang disampaikan oleh informan "M" sebagai berikut: "saya tidak mengetahui alat dan bahan untuk mandi saya juga tidak mempersiapkan alat dan bahan untuk mandi saya langsung masuk saja kekamar mandi" (17 Juni 2019).

Sedangkan informan "R": kalau mau mandi pakai sabun, odol, sikat gigi, malas pakai sampo" (17 Juni 2019).

Berdasarkan hasil wawancara yang dilakukan peniliti terhadap informan " $A$ " dan " $R$ " mampu menggunakan sabun mandi, menyikat gigi menggunakan odol, keramas menggunakan shampo, dan memakai handuk setelah mandi, sebagai berikut: "pada saat saya mandi menggunakan sabun mandi menyikat gigi menggunakan odol dan keramas menggunakan shampo, setelah mandi saya mengeringkan badan menggunakan handuk" (17 Juni 2019).

Lain halnya yang disampaikan oleh informan "M" sebagai berikut: "pada saat mandi, saya mandi menggunakan sabun mandi, menyikat gigi menggunakan odol, dan keramas menggunakan shampo dari alat dan bahan teman saya yang sudah tersedia dikamar mandi" (17 Juni 2019).

Berdasarkan hasil wawancara yang dilakukan peniliti terhadap informan "A" mampu melakukan perawatan mandi setiap hari dan informan "A" Nampak bersih dan wangi, sebagai berikut:

"saya melakukan perawatan mandi setiap hari pukul 08.00" (17 Juni 2019).

Lain halnya yang disampaikan oleh informan "M" dan "R" sebagai berikut: "saya malas mandi setiap hari karena apabila saya sudah mandi hari ini saya tidak mau mandi lagi karena itu sama saja" (17 Juni 2019)..

2. kemampuan berhias

Berdasarkan hasil wawancara yang dilakukan peneliti kepada informan " $\mathrm{A}$ " tidak mampu mejawab pertanyaan yang di berikan yaitu mengenai manfaat dan tujuan perawatan berhias itu apa, sebagai berikut: "sama halnya dengan manfaat dan tujuan mandi saya juga tidak pernah dijelaskan sebelumnya dengan perawat manfaat dan tujuan perawatan berhias itu apa"(17 Juni 2019)

Sama halnya yang disampaikan oleh informan "M" dan "R" senanda yang telah disampaikan oleh informan "A" sebagai berikut: "saya tidak mengetahui apa itu manfaat dan tujuan perawatan berhias karena saya tidak pernah diberitahu"(17 Juni 2019)

Berdasarkan hasil wawancara yang dilakukan peneliti kepada informan "A" mampu menyebutkan dan mempersiapkan alat dan bahan untuk berhias serta mampu mengganti pakaian bersih, sebagai berikut: "alat dan bahan untuk berhias yang biasa saya siapkan itu seperti baju dan celana bersih saya dipakai sehabis mandi, sisir untuk merapikan rambut"(17 Juni 2019)

Lain halnya yang disampaikan oleh informan "M" sebagai berikut: "saya tidak mengetahui alat dan bahan untuk berhias dan saya tidak pernah mempersiapkan alat dan bahan untuk berhias karena sehabis mandi saya tidak mengganti baju dan celana saya karena tidak tersedianya alat dan bahan dan menurut saya mau diganti atau tidak diganti semuanya sama saja"(17 Juni 2019)

Sedangkan yang disampaiakan informan "R" sebagai berikut: habis mandi pakai aja baju yang ada" (17 Juni 2018) 
Berdasarkan hasil wawancara yang dilakukan peneliti kepada informan "A" mampu menggunakan pakaian dengan baik dan benar, sebagai berikut: "saya mengancing baju saya satu persatu dari atas kebawah dan meresleting atau mengikat celana saya agar tidak melorot"

senanda halnya yang disampaikan oleh informan " $M$ " dan "R" senada yang disampaikan oleh informan "A" sebagai berikut: "menggunakan pakaian yang baik dan benar seperti pakai baju dan celana" (17 Juni 2019)

b. Hasil Observasi pasien isolasi sosial dengan pemenuhan kebutuhan mandi dan berhias

1. Kemampuan mandi

a) Kemampuan menyebutkan manfaat dan tujuan mandi:

Berdasarkan hasil observasi yang dilakukan peneliti terhadap informan "A", "M" dan "R" pada saat dilakukan wawancara mengenai manfaat dan tujuan mandi di dapatkan informan "A" dan informan "M" tidak mampu menjawab dengan alasan yang senada yaitu kedua informan tidak pernah mendapatkan penjelasan mengenai manfaat dan tujuan mandi itu apa dari orang terdekat seperti perawat dan keluarga sedangkan informan "R" tau mamfaat mandi hanya merasa malas. Pada saat peneliti melakukan observasi mengenai hal tersebut didapatkan bahwa kurangnya pendekatan perawat terhadap informan karena pada saat melakukan perawatan diri mandi perawat hanya menginstruksikan pada pasien dan tidak terlalu memantau apakah pasien sudah mandi dengan benar atau belum.

b) Kemampuan Menyebutkan dan mempersiapkan alat dan bahan untuk mandi:

Pada saat peneliti melakukan observasi pada tanggal 17 Juni 2019 terhadap ketiga informan di dapatkan bahwa informan "A" dan "R" mampu menyebutkan dan mempersiapkan alat dan bahan untuk mandi dilihat dari informan " $A$ " dan "R" mampu mengambil dan mempersiapkan alat dan bahan untuk mandi pada saat setiap ingin melakukan perawatn diri mandi yang telah disediakan di atas meja oleh perawat. Namun lain halnya dengan informan "M" pada saat dilakukan observasi pada tanggal 17 Juni 2019 informan "M" tidak mampu menyebutkan dan mempersiapkan alat dan bahan untuk mandi dilihat dari kurangnya kedekatan perawat dalam memberikan pengetahuan dan juga informan " $M$ " tidak pernah mempersiapkan alat dan bahan untuk mandi pada saat ingin melakukan perawatan mandi sehingga informan " $\mathrm{M}$ " tidak mampu menyebutkan dan mempersiapkan alat dan bahan untuk mandi. c) Kemampuan Menggunakan alat dan bahan untuk mandi:

Pada saat dilakukan observasi pada tanggal 17 Juni 2019 bahwa informan "A" dan "R" mampu menggunakan alat dan bahan untuk mandi sesuai dengan yang di kroscek dengan hasil wawancara bahwa informan " $\mathrm{A}$ " dan "R" mandi menggunakan sabun mandi, sikat gigi menggunakan odol, keramas menggunakan shampo, dan mengeringkan badan menggunakan handuk dilihat dari setelah mandi badan informan "A" dan "R" Nampak bersih, gigi bersih, rambut bersih, tidak berbau dan tidak berketombe. Lain halnya dengan informan "M" pada saat dilakukan observasi tidak mampu menggunakan alat dan bahan untuk mandi di dapatkan pada saat observasi informan "M" tidak membawa alat dan bahan untuk mandi karena informan"M" tidak mengambil dan mempersiapkan alat dan bahan yang telah disediakan oleh perawat di atas meja pada saat ingin ke kamar mandi, Nampak informan "M" langsung masuk saja ke kamar mandi.

d) Kemampuan melakukan perawatan mandi setiap hari:

Pada saat dilakukan observasi ternyata apa yang telah di sampaikan informan "A"mengenai dirinya mampu melakukan perawatan diri mandi setiap hari sesuai dengan apa yang disampaikan pada saat wawancara yaitu diobservasi dari informan "A" selalu hadir pada saat jadwal mandi dan juga informan " $A$ " Nampak bersih, mulut dan badan tidak bau. Sedangkan pada saat dilakukan observasi terhadap informan " $M$ " dengan kemampuan melakukan perawatan mandi setiap hari informan "M" tidak mampu dengan hasil observasi informan "M" Nampak malas dan perlu paksaan pada saat di suruh mandi, dan pada saat observasi informan "M" juga Nampak kotor, bau badan dan mulutnya bau pada saat sesi wawancara. Lain halnya dengan informan "R" yang saat observasi mampu menyebutkan mamfaat mandi dan tau apa alat dan bahan saat mandi namun informan " $R$ " nampak malas untuk mandi dan perlu sedikit paksaan pada saat disuruh mandi.

2. Kemampuan berhias

a.) Kemampuan manfaat dan tujuan berhias:

Berdasarkan hasil observasi yang dilakukan peneliti terhadap informan "A", "M" dan "R" pada saat dilakukan wawancara mengenai manfaat dan tujuan berhias di dapatkan ketiga informan tidak mampu menjawab dengan alasan yang senada yaitu tidak pernah mendapatkan penjelasan mengenai manfaat dan tujuan berhias itu apa, pada saat peneliti melakukan observasi mengenai hal tersebut didapatkan bahwa kurangnya pendekatan perawat dengan ketiga informan dimana perawat hanya menginstruksikan tanpa memberikan penjelasan. 
b.) Kemampuan menyebutkan dan mempersiapkan alat dan bahan untuk berhias

Pada saat dilakukan observasi tanggal 18 Juni 2018 didapatkan bahwa informan "A" mampu menyebutkan dan mempersiapkan alat dan bahan berhias sesuai yang di sampaikan pada saat wawancara pada tanggal 17 juni 2019 informan "A" mampu menyebutkan dan mempersiapkan alat dan bahan berhias seperti baju bersih, celana bersih dan sisir yang merupakan alat dan bahan yang biasa informan " $A$ " siapkan pada saat setelah mandi dan ingin melakukan perawatan berhias dilihat dari informan "A" mengambil pakaian ganti dari tasnya. Lain halnya dengan informan " $M$ " dan "R" pada saat dilakukan observasi pada tanggal 18 Juni 2019, informan "M" dan "R" tidak mampu menyebutkan dan mempersiapkan alat dan bahan berhias dilihat dari informan "M" dan "R" tidak mengganti pakaian setelah mandi karena alasan informan malas dan diganti tidak diganti sama saja.

c.) Kemampuan menggunakan alat dan bahan untuk berhias

Berdasarkan hasil observasi terhadap informan "A" yang dilakukan pada tanggal 18 Juni 2019 didapatkan bahwa informan " $A$ " mampu melakukan perawatan berhias sesuai yang disampaikkan pada saat dilakukan wawancara dilihat dari informan " $A$ " mengganti pakaian kotornya dengan pakaian yang bersih sehabis mandi dengan mengambil pakaian bersih dari dalam tasnya, serta informan " $A$ " juga mampu merapikan rambutnya dengan cara disisir Nampak dari rambut informan "A" rapi, pakaian informan tampak rapi dan tidak acak-acakan. Sedangkan pada saat dilakukan observasi terhadap informan "M" dan "R" pada tanggal 18 Juni 2019 didapatkan bahwa informan "M" dan "R" tidak mampu menggunakan alat dan bahan untuk berhias dengan informan "M" dan "R" tampak tidak rapi dan tidak bersih, rambut tidak disisir dan kuku agak panjang, informan "M" dan "R" juga nampak tidak mengganti pakaiannya dengan pakaian yang bersih karena informan " $M$ " dan " $R$ " nampak malas melakukan aktivitas dan kebanyakan menghabiskan waktu di dalam kamar saja.

\section{PEMBAHASAN}

Keterbatasan perawatan diri biasanya diakibatkan karena stressor yang cukup berat dan sulit ditangani oleh pasien sehingga pasien tidak mau mengurus atau merawat dirinya sendiri baik dalam hal mandi, berpakaian, berhias, makan, maupun BAB dan BAK. Berdasarkan hasil pengamatan dari 3 informan didapatkan hasil informan " $\mathrm{A}$ " mampu melakukan perawatan diri (mandi), mampu melakukan kegiatan mandi, mampu menyebutkan alat dan bahan untuk mandi, mampu mempersiapkan peralatan mandi, pada saat mandi pasien menyikat gigi, pakai sabun dan keramas, pasien mampu melakukan perawatan diri mandi sehari-hari walaupun pasien belum mengerti manfaat dan tujuan mandi. Sedangkan informan "M" tidak mampu melakukan perawatan mandi, tidak mengerti manfaat dan tujuan mandi, begitupun dentgan menyiapkan alat dan bahan untuk mandi dan cara mandi yang benar mulai dari sikat gigi, keramas, dan menggunkan sabun. Lain halnya dengan informan "R" yang tau mamfaat mandi, mampu menyebutkan alat dan bahan untuk mandi, pasien mampu mempersiapkan peralatan mandi, pada saat mandi pasien menyikat gigi, pakai sabun dan keramas namun nampak malas mandi dan perlu dipaksa agar mau mandi. Dari masalah di atas dapat disimpulkan bahwa dua dari tiga informan memiliki masalah yang sama yaitu tidak mengetahui manfaat dan tujuan mandi. Salah satu informan mengungkapkan bahwa ia tidak mengetahui manfaat dan tujuan mandi dikarenakan pasien tidak pernah diberitahu oleh perawat manfaat dan tujuan mandi. Pernyataan ini didukung oleh teori yang mengungkapkan bahwa salah satu faktor predisposisi yang menyebabkan kurangnya perawatan diri pasien adalah kurangnya dukungan motivasi dan pemberian pengetahuan kemampuan diri pasien ( Damaiyanti, 2014 ). Perawat sebagai orang terdekat pasien di rumah sakit untuk berinteraksi, perawat harus mampu memberikan perhatian kepada pasien tentang pemenuhan kebutuhan diri pasien khususnya dalam pemenuhan kebutuhan perawatan diri mandi dan berhias. Dengan pengetahuan yang baik pasien mampu melakukan perawatan diri secara mandiri dan terus menurus setiap harinya. Hal ini didukung teori (Deden Dermawan, 2013) yang mengatakan bahwa salah satu faktor prespitasi pemenuhan kebutuhan diri pasien dengan difisit perawatan diri adalah pengetahuan, pengetahuan personal hygiene sangat penting karena pengetahuan yang baik dapat meningkatkan kesehatan.

Berdasarkan hasil pengamatan dari 3 informan didapatkan hasil informan " $A$ " mampu melakukan perawatan diri (berhias), mampu menyebutkan dan menyiapkan alat dan bahan untuk berhias, memakai pakaian dengan rapi, menyisir dan merapikan rambut, nanmun kuku nampak panjang karena tidak ada pemotong kuku juga tidak mengerti tentang manfaat berhias. Sedangkan informan "M" tidak mampu melakukan perawatan berhias, tidak mengerti manfaat dan tujuan berhias, begitupun dengan menyiapkan alat dan bahan untuk berhias dan cara berpakaian yang baik, pasien juga nampak tidak rapi dan kuku agak panjang. Sama hal nya dengan informan "R" tidak mampu melakukan perawatan berhias, kuku agak panjang, tidak mengerti manfaat dan tujuan berhias, begitupun dengan menyiapkan alat dan bahan untuk berhias, 
meski tau cara berpakaian yang baik namun pasien tidak mengganti pakaian setelah mandi dan memakai pakaian yang sebelumnya dia pakai. Berdasarkan hasil tersebut didapatkan keselarasan teori yaitu gangguan defisit perawatan diri didapatkan karakteristik fisik badan kotor dan berbau, rambut kotor, kuku panjang dan kotor, penampilan tidak rapi (Tarwoto dan Wartono, 2012). Menurut peneliti dengan perlunya peningkatan dukungan dan motivasi dan pemberian pengetahuan tentang perawatan diri dari perawat akan mampu meningkatkan kemampuan pasien dalam merawat dirinya serta ketersedian alat dan bahan yang diperlukan pasien dalam memenuhi kebutuhan perawatan diri pasien yang disediakan oleh pihak rumah sakit mampu membantu pasien dalam memenuhi kebutuhan perawatan dirinya sehingga pasien dapat terpenuhi kebutuhan perawatan dirinya, menjadi tahu cara perawatan diri dan menjadi terbiasa dalam melakukan perawatan diri khususnya mandi dan berhias setiap hari.

\section{KESIMPULAN}

Berdasarkan hasil penelitian yang didapatkan keimpulan bahwa pasien yang malas beraktivitas dan tidak mampu bersosialisasi tidak mampu melakukan pemenuhan kebutuhan defisit perawatan diri mandi dan berhias klien karena kurangnya dukungan motivasi, pemberian pengetahuan, serta kurangnya ketersediaan alat dan bahan perawatan diri khususnya mandi dan berhias.

\section{SARAN}

1. Bagi Institusi diharapkan agar menjadikan karya tulis ilmiah ini sekalipun jauh dari kata sempurna diharapkan dapat dijadikan sebagai bahan kajian dan masukan untuk pengembangan ilmu pengetahuan serta sebagai bacaan untuk penelitian selanjutnya.
2. Bagi Rumah Sakit diharapkan sebaiknya pihak rumah sakit lebih bias untuk meningkatkan kualitas dalam hal pelayanan diantaranya menambah jumlah tenaga perawat professional serta mengontrol hasil dari kegiatan tenaga perawatnya dan juga menyediakan alat dan bahan yang diperlukan pasien khususnya dalam memenuhi kebutuhan perawatan dirinya.

3. Bagi Perawat khususnya yang bertugas di ruangan Seruni diharapkan untuk lebih mendekatkan perhatianya dalam kebersihan diri pasien yang tidak mampu melakukan perawatan diri serta diharapkan juga perawat mampu mempertahankan kebersihan diri pasiennya yang sudah mampu.

4. Bagi Pasien diharapkan mampu meningkatkan perawatan dirinya serta mampu pula mempertahankan perawatan dirinya.

5. Bagi Keluarga diharapkan keluarga mampu membuat pasien membantu proses penyembuhan pasien dengan dukungan serta perhatian dan empati melalui kunjungan berkala.

\section{UCAPAN TERIMA KASIH}

1. Ketua Jurusan Keperawatan Poltekkes Kemenkes Makassar yang telah memberikan kesempatan melakukan penelitian

2. Direktur Politeknik Kesehatan Kemenkes Makassar yang telah memberikan kesempatan melakukan penelitian

3. Direktur Rumah Sakit Tk. II Pelamonia yang telah memberikan fasilitas ke pasien melakukan penelitian

4. Para perawat di Ruang Perawatan Jiwa yang telah membantu dan mengarahkan jalannya penelitian

5. Rekan/teman-teman dosen yang telah memberikan masukan dan motivasi dalam penelitian ini

\section{DAFTAR PUSTAKA}

Zelika, Dermawan A., A., Deden., Kajian Asuhan Keperawatan Jiwa Halusinasi Pendengaran Pada Sdr . D Di Ruang Nakula Rsjd Surakarta ( Study of Nursing Care Mental of Auditory Hallucinations on Mr D in the Nakula Rsjd of Surakarta, PROFESI, Volume 12, Nomor 2,Maret 2015 KAJIAN

Damaiyanti, (2014). Asuhan Keperawatan Jiwa, Bandung: Refika Aditama

Katrili, R., (2015). Pengaruh Pemberian Pendidikan Kesehatan pada Pasien Gangguan Jiwa Defisit Perawatan Diri Terhadap Pelaksanaan ADL Activity Of Dayli Living Kebersihan Gigi dan Mulut di RSJ Prof.Dr. V. L Ratumbuysang Ruang Katrili, Jurnal Keperawatan Unsrat

Madalise, S., Bidjuni H., Wowiling,F., (2015). Pengaruh Pemberian Pendidikan Kesehatan pada Pasien Gangguan Jiwa Defisit Perawatan Diri Terhadap Pelaksanaan Activity of Dayliliving Kebersihan Gigi dan Mulut di RSJ. Prof.Dr. V. L Ratumbuysang Ruang Katrili, ejournalKeperawatan (e-Kp) Volume 3 Nomor 2, Mei 2015.

Nurjannah, I. 2005. Pedoman Penanganan Gangguan Jiwa: Manajemen Proses Keperawatan dan Hubungan 
Jurnal Media Keperawatan: Politeknik Kesehatan Makassar

Vol. 10 No. 022019

e-issn : 2622-0148, p-issn : 2087-0035

Terapeutik Perawat - Klien. Yogyakarta: Moco Media.

Rochmawati, D.,H., Keliat, B., A., Wardani, I.,Y., (2013). Manajemen Kasus Spesialis Jiwa Defisit Perawatan Diri pada Klien Gangguan Jiwa di RW 02 dan RW 12 Kelurahan Baranangsiang Kecamatan Bogor Timur

Tarwoto dan Wartono.(2010). Kebutuhan Dasar Manusia Dasar Manusia Dan Proses Keperawatan.Edisi 4.salemba Medika : jakarta 